\title{
Improving the Efficiency of Energy Storage System Using Compressed Carbon Dioxide in a Three Stage Turbine and Two Saline Aquifers System with Different Pressure Gradient
}

\author{
Omar Hamouda ${ }^{1}$, Dr. Ayman Abbas ${ }^{2}$, Prof. Ahmed Attia ${ }^{3}$ \\ The British University in Egypt, Cairo, Egypt ${ }^{1,2}$ \\ Benha University, Cairo, Egypt ${ }^{3}$
}

\begin{abstract}
Compressed air energy storage systems are an ideal solution to large scale energy storage problem. One of their major advantages is the ease of regulating electricity depending on the demand/load. However, their low thermal efficiency and low energy storage density limit their applications. A solution has been proposed to this major problem by implementing a three-stage compressor with a second recuperator and heat exchanger added after each stage, followed by a three-stage turbine and two reservoirs storage system for trans critical $\mathrm{CO}_{2}$. Furthermore, a three-stage compressor, two stage turbine and two-level storage reservoir system was investigated for supercritical and trans critical air. A thermodynamic and parametric analysis was performed. The study revealed that trans critical $\mathrm{CO}_{2}$ with the respective system has higher round trip efficiency and higher exergy efficiency by ranges of at least $15 \%$ compared to all of the existing systems. Also, an additional 28\% of mechanical work was recovered in comparison to the unmodified system. Additionally, the study showed that the supercritical air for the corresponding system failed to provide any commercial benefits as its thermodynamic cycle proved unsustainable.
\end{abstract}

Keywords: Energy Storage, Thermodynamic Analysis, Parametric Analysis, Round Trip Efficiency, Exergy Efficiency, Exergy Destruction Ratio

\section{I.INTRODUCTION}

Alternative energy resources such as solar and wind energy have gained significant importance due to their potential to minimise the greenhouse effect by reducing carbon footprints [1] [2]. However, these energy resources are intermittent and unable to provide a continuous energy supply due to the non-uniform weather conditions and other beyond humancontrolled circumstances. Moreover, it is difficult for these energy resources to match the periodic electric demand [3] [4]. This problem can be encountered with the deployment of energy storage systems (ESS). The choice of ESS depends on the energy requirements, geographic location, startup time and other similar factors [5].

For industrial applications, compressed air energy storage systems (CAES) have been proposed and supported by several researchers as CAES are capable of regulating a large amount of electric power with respect to the variable energy demand [6] [7] [8].

The three primary subcategories of CAES are; diabatic, adiabatic and isothermal CAES systems. This division depends on the method of dealing with the heat during compressions and before expansion. Diabatic CAES (D-CAES) systems lose the heat of compression to the ambient by cooling down the compressed air. This requires external heating of the air before the discharge process to prevent icing of the expansion machinery. Adiabatic CAES (A-CAES) systems utilise additional thermal energy storage (TES) devices to store the compression heat and release the heat to air in the discharge phase before expansion. Isothermal CAES (I-CAES) depends on eliminating the compression heat out of the process. System factors such as cycle efficiency, energy density and start-up time are varied among the different concepts as well as their development status and application fields [9]. Existing application of some of these CAES systems can be seen in the German village of Huntorf with a 290 MW power plant [10] and in McIntosh/Alabama in the USA with a 110 MW power plant [11]. However, the major drawback of these systems is their low thermal efficiency i.e. 42\%. Despite the availability of large storage reservoirs and abundance of porous media that are necessary for these systems, the $\mathrm{CO}_{2}$ emission from combustion and the need for material that can resist high process temperatures, limit the application of these plants [12].

To overcome the disadvantages of A-CAES, dedicated TES systems were proposed because the cycle efficiency is not reliant on the absolute storage temperature. However, a small drop in cycle efficiency at lower storage temperatures was observed due to the energy losses during extra heat exchange processes [13]. Efficient heat transfer becomes possible by marginally increasing the temperature of the cycle by using commercial pistons which are available in the market. Nonetheless, the safety concerns and high initial costs limit the use of such plants on a commercial level [9]. 


\section{International Advanced Research Journal in Science, Engineering and Technology}

Vol. 8, Issue 2, February 2021

\section{DOI: $10.17148 / I A R J S E T .2021 .8205$}

Hence, out of all the available concepts, the two practical approaches at a commercial level for using compressed air storage are; constant volume (isochoric), and constant pressure (isobaric). The cyclic compression and expansion during isochoric processes have a negative effect on the machinery as they operate out of their design pressure ratio. Thus these systems tend to have lower efficiencies, limiting the use in modern application [14]. On the other hand, the isobaric systems have enormous setup costs, disqualifying them for commercial applications [14]. Nevertheless, the researchers investigated these systems in details, and established that storage systems using aquifers can potentially perform better, mainly when the storage comprises of two reservoirs at different pressure levels [15]. These claims are backed up by several numerical simulation studies [12] [16] [17]. Despite all these efforts, the researchers failed to; minimise the high setup cost, reduce the startup time, and reduce the higher facility requirements.

Compressed carbondioxide $\left(\mathrm{CO}_{2}\right)$ was proposed as an alternative to compressed air as a working fluid for similar storage systems. It has been claimed that $\mathrm{CO}_{2}$ behaves in a non-ideal manner at the necessary conditions and is more efficient in Brayton cycles compared to the standard air [18]. Apart from efficiency, the overall performance of the system improves using compressed $\mathrm{CO}_{2}$ compared to conventional A-CAES system [19]. Above all, greenhouse gas emissions are reduced due to geological sequestration of $\mathrm{CO}_{2}$ into deep formations such as saline aquifers, gas and oil reservoirs, and coal beds [20]. In [29], Liu proposes a novel liquid $\mathrm{CO}_{2}$ energy storage system with high capacity, where an ejector cycle for condensing $\mathrm{CO}_{2}$ during discharging is introduced. An increase in the turbine inlet pressure improves the net power output and the round-trip efficiency. As ejector back pressure is increased, the ejector entrainment ratio decreases and the exergy destruction ratio is decreased. The electrical thermal storage is also found to be the component causing the largest exergy destruction.

Borgia and Goldenburg conducted the exergy analysis of a closed-loop gas storage system composed of two reservoirs, particularly saline aquifers at different depths. Trans critical and supercritical $\mathrm{CO}_{2}$ were used as the working fluid in this system. Parametric analysis was performed to determine the effects on the two saline aquifers. The other parameters include the energy storage pressure, energy-releasing pressure and the pressure of the low reservoir pressure. The analysis also includes the effect of these parameters on system performance [21]. The results from [21] showed that the energy storage density was higher for both the trans critical $\left(497.68 \mathrm{kWh} / \mathrm{m}^{3}\right)$ and supercritical $\left(255.20 \mathrm{kWh} / \mathrm{m}^{3}\right) \mathrm{CO}_{2} \mathrm{systems}$ compared the conventional CAES $\left(2-20 \mathrm{kWh} / \mathrm{m}^{3}\right)$. The round-trip efficiency was $63.35 \%$ for the trans critical $\mathrm{CO}_{2}$ and $62.28 \%$ for the supercritical $\mathrm{CO}_{2}$. The exergy efficiency was $53.02 \%$ for the trans critical $\mathrm{CO}_{2}$ and $51.56 \%$ for the supercritical $\mathrm{CO}_{2}$ compared to $81.7 \%$ conventional CAES. Although the systems showed these advantages, they need to be installed close to the surface, which increases not only environmental concerns but also requires more space. In [26], Liu analyses a $10 \mathrm{MW}$ output power production by novel approaches. These approaches are based on whether exergy destruction is avoidable/unavoidable and whether it is endogenous/exogenous. Results suggested that the compressor has the biggest stake in the overall exergy destruction and that turbines have the most room for improvement. In [27], Liu analyses a novel two-stage trans critical compressed carbon dioxide energy storage system using conventional and advanced exergy analyses. The cold storage is found to be the component with the largest exergy destruction rate using the conventional method, while the advanced method identifies more accurately the first compressor as the component with the highest avoidable exergy destruction rate. The exergy efficiency also has room for improvement as a result of the analysis.

Alternatively, it has been demonstrated from the thermal analysis and mathematical modelling of the CAES systems that a deep insight into the system performance can be shown and this can help in the selection of working fluids [5] [6] [7]. Using similar performance criteria presented in [21] [22] [23], a study was conducted to investigate the system performance of a three stage compressor and a two stage turbine system using trans critical and supercritical $\mathrm{CO}_{2}$ with two reservoirs as saline aquifers. It was also shown that the study was equally transferable to caverns with high round trip and exergy efficiencies [21]. In [28], Liu uses a genetic algorithm to analyse the thermodynamic efficiency and cost evaluation of a novel Compressed Carbon dioxide Energy Storage (CCES) system. An increase in the turbine inlet temperature is found to have the most positive effect on the net output power as well as a decrease in the unit product cost.

Nonetheless, to the best of our knowledge based on the literture review of published work, a three-staged turbine system has not been modelled and parametrically studied. It has been claimed by some researchers that the system efficiency increases with the increase in the number of turbines with proper temperature and pressure regulation [24] [25].

The novelty of this study lies in this area, where, trans critical $\mathrm{CO}_{2}$ has been studied using parametric analysis for three staged compressor and three staged turbine system. Additionally, supercritical air and trans critical air are modelled using three staged compressor and two stagged turbine system. The system studied consists of two saline aquifers at different pressure levels. The effect of change in pressure with respect to, the energy storage pressure, energy releasing pressure and low pressure reservoir on system components, has been investigated here.

\section{II.SYSTEM DESCRIPTION}

The system [21] used to verify the current model consisted of two saline aquifers, three stage compressors with intercooler, recuperator, heaters, and a two stage turbine with heat recovery systems (Figure 1), named as the existing system. Trans critical carbon dioxide $\left(\mathrm{CO}_{2}\right)$ was used to compare the results from [21] with a current model developed 


\section{DOI: 10.17148/IARJSET.2021.8205}

in Engineering Equation Solver (EES) in order to validate the current model. The newly verified model was used to investigate the possibility of trans critical and supercritical air as a working fluid following the closed energy storage cycle offered by [21].

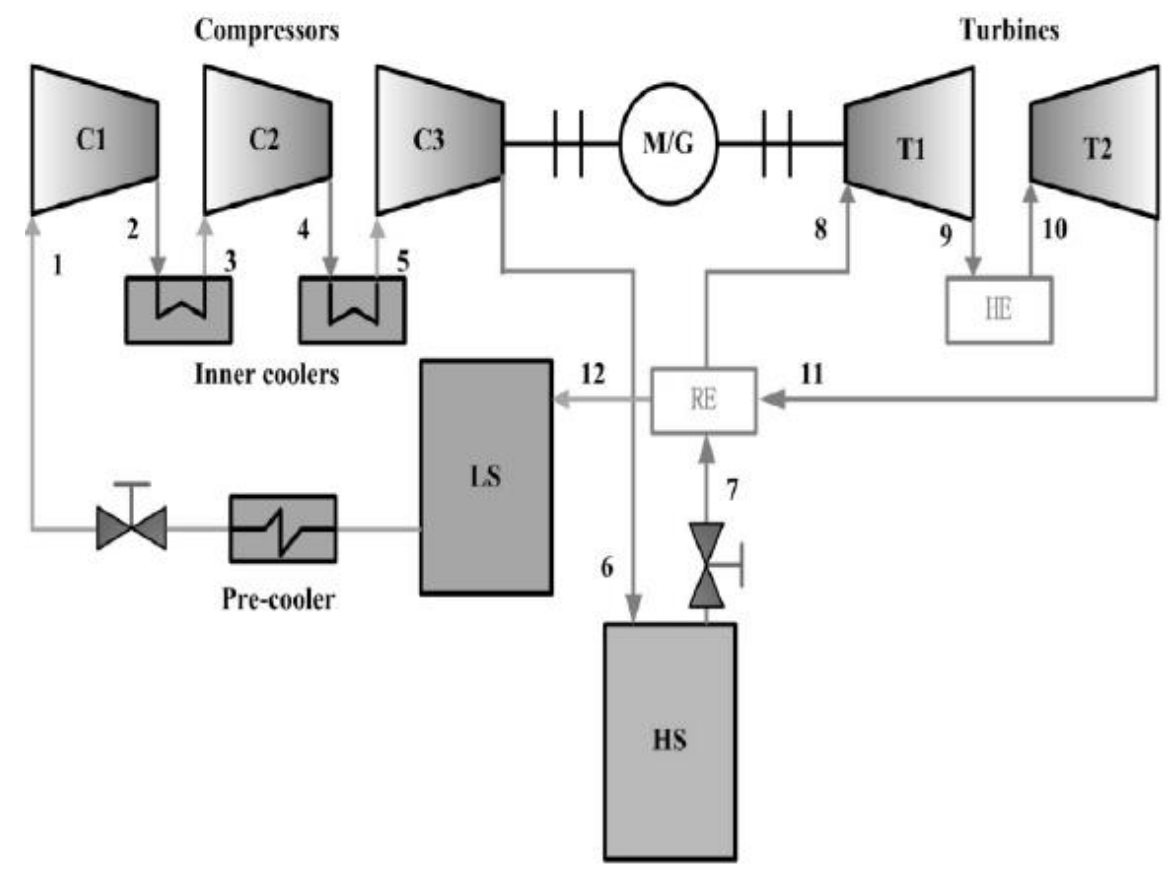

Figure 1: The schematic of TC-CCES (reproduced from [1])

The novelty in the proposed system is that it is modified with an additional turbine and an additional recuperator after each compressor (Figure 2) expecting the system efficiency improvement, henceforth named as a modified system. All the theoretical modelling steps were followed as in [21] to study the effects of trans critical $\mathrm{CO}_{2}$ through the modified system This fluid and system will be referred to as $\mathrm{TC}-\mathrm{CO}_{2} \mathrm{M}$. The working fluids nomenclature with respect to the systems is presented in Table 1.

Table 1: System and working fluid-based nomenclature

\begin{tabular}{lll}
\hline Working fluid & Configuration & Nomenclature \\
\hline $\begin{array}{l}\text { Trans critical carbon } \\
\text { dioxide }\end{array}$ & $\begin{array}{l}\text { Three compressors and two } \\
\text { turbines }\end{array}$ & TC-CO \\
Trans critical air & $\begin{array}{l}\text { Three compressors and two } \\
\text { turbines }\end{array}$ & TC-Air \\
Supercritical air & $\begin{array}{l}\text { Three compressors and two } \\
\text { turbines }\end{array}$ & SC-Air \\
$\begin{array}{l}\text { Thrans critical carbon } \\
\text { dioxide }\end{array}$ & \begin{tabular}{l} 
turbines \\
\hline
\end{tabular} & TC-CO $\mathrm{CO}_{2} \mathrm{M}$ \\
\hline
\end{tabular}

The system model connecting the mass flow, upper temperature difference, lower temperature difference and other parameters is explained in [21]. The validated model was used to conduct a similar analysis for trans critical air (TCAir) and supercritical air (SC-Air), whereas the modified system was studied for trans critical $\mathrm{CO}_{2}$. T-S diagrams for the mentioned fluids are presented in Figure 3. It can be seen that SC-Air cannot be used in the cycle as it is not thermodynamically sustainable. On the other hand, TC-Air and $\mathrm{TC}-\mathrm{CO}_{2} \mathrm{M}$ are sustainable. After this fluid qualification, only the results of TC-Air and TC- $\mathrm{CO}_{2} \mathrm{M}$ along with a detailed comparison with $\mathrm{TC}-\mathrm{CO}_{2}$ are presented here. 


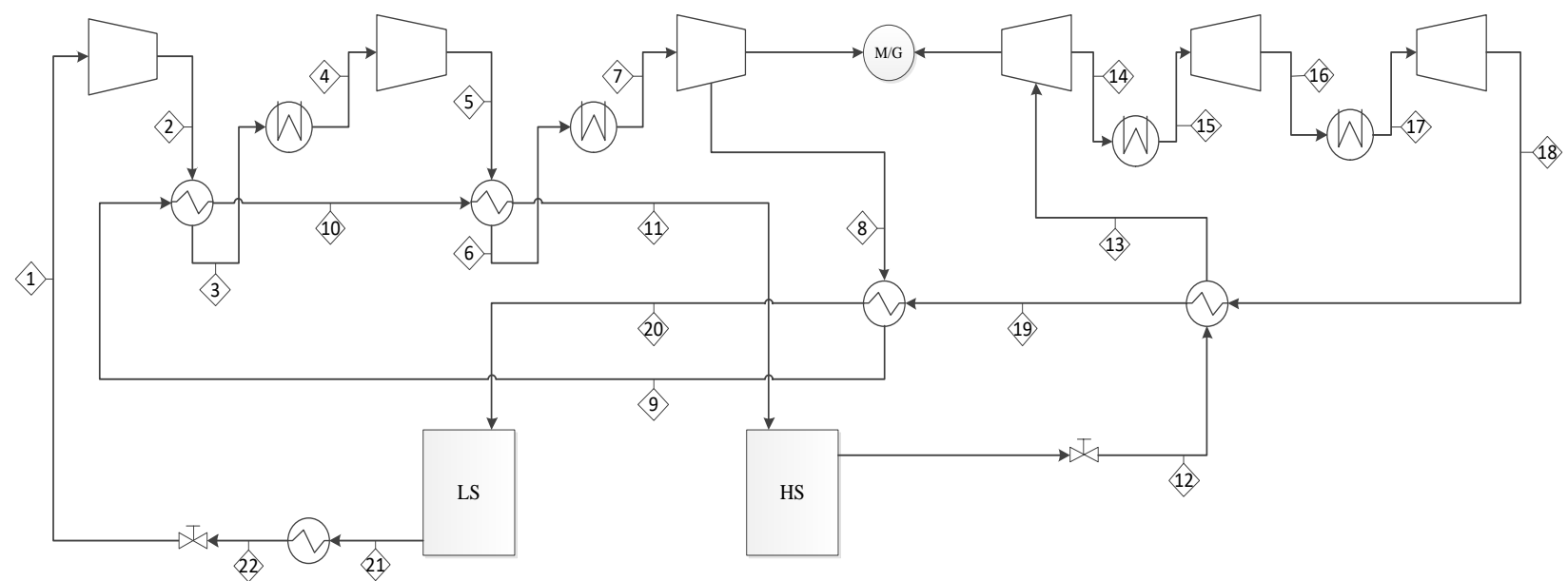

Figure 2: The schematic of three stage turbine system
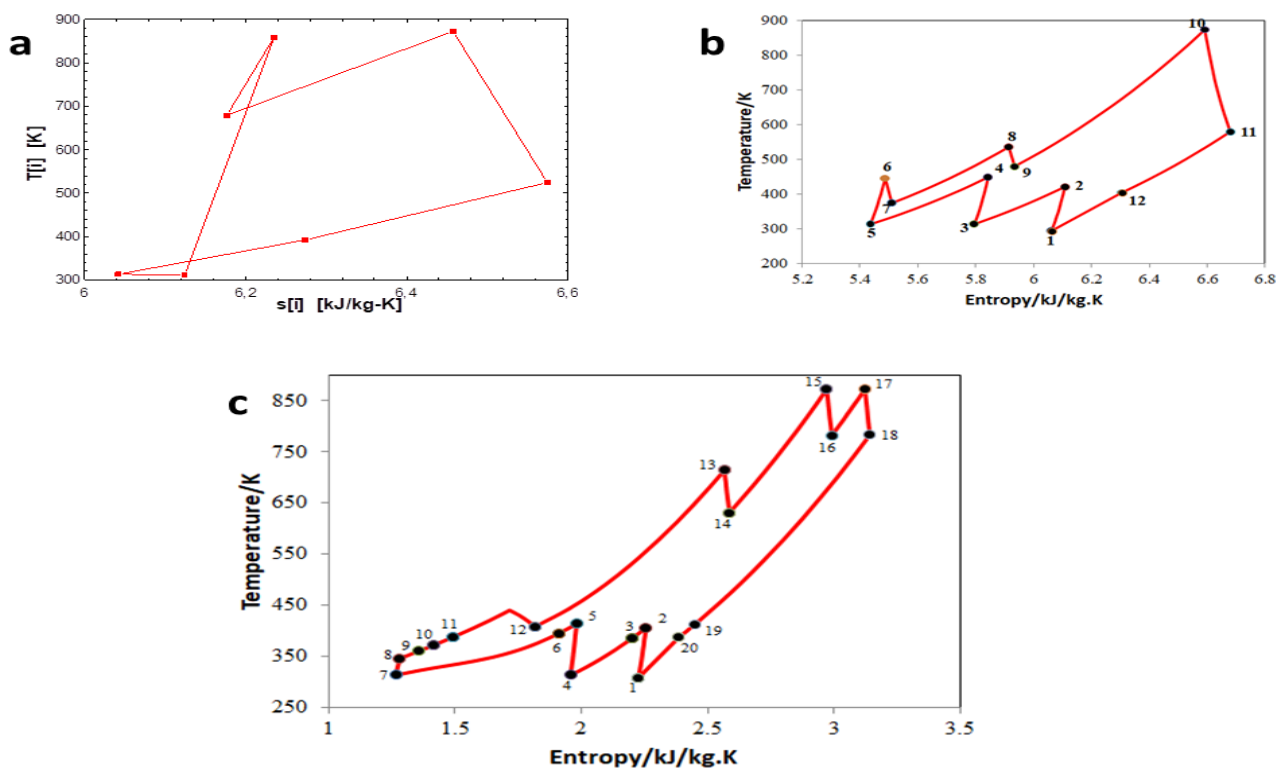

Figure 3: T-S diagram a) SC-Air, b) TC-Air and c) TC- $\mathrm{CO}_{2} \mathrm{M}$

\section{III.RESULTS AND DISCUSSIONS}

The parametric study was carried out using Engineering Equation Solver (EES) software. All thermodynamic properties are given in the material library of the EES database [26].

\section{i.Thermodynamic analysis}

The thermodynamic parameters at each node of corresponding systems and fluids: TC-Air and TC-CO $\mathrm{C}_{2} \mathrm{M}$, are presented in Table 2 and Table 3, respectively. The comparison of TC-Air with [21] is analogous to each other due to the same number of the nodes (12), however, the node-based comparison of [21] with the TC- $\mathrm{CO}_{2} \mathrm{M}$ is only possible up to node 11. Whereby, the presence of the third stage turbine adds additional nodes to the modified system. Nonetheless, roundtrip and exergy efficiencies, energy density and destruction ratio are comparable. Energy and exergy analysis results are given in

Table 4. It should be noted that the third turbine (T3) and thermal input 2 are available in the modified system only. Exergy destruction ratio of different components of each system and fluid are presented in Table 5 and shown in

\begin{tabular}{lccc}
\hline Component & $\mathrm{TC}-\mathrm{CO}_{2} \mathrm{M}$ & $\mathrm{TC}-$ Air & $\mathrm{TC}-\mathrm{CO}_{2}$ \\
\hline Compressor & $23.46 \%$ & $26.92 \%$ & $7.03 \%$ \\
Recuperator & $2.95 \%$ & $9.53 \%$ & $11.77 \%$ \\
Turbine & $8.65 \%$ & $10.64 \%$ & $6.56 \%$ \\
Heater & $1.28 \%$ & $26.19 \%$ & $61.79 \%$ \\
Low pressure reservoir & $3.99 \%$ & $4.01 \%$ & $7.03 \%$ \\
High pressure reservoir & $53.08 \%$ & $29.28 \%$ & $5.25 \%$ \\
\hline
\end{tabular}




\section{International Advanced Research Journal in Science, Engineering and Technology}

Vol. 8, Issue 2, February 2021

DOI: $10.17148 /$ IARJSET.2021.8205

$\square \mathrm{C} \backsim \mathrm{RE} \backsim \mathrm{T} \backsim \mathrm{HE} \backsim \mathrm{LS} \sim \mathrm{HS}$

a

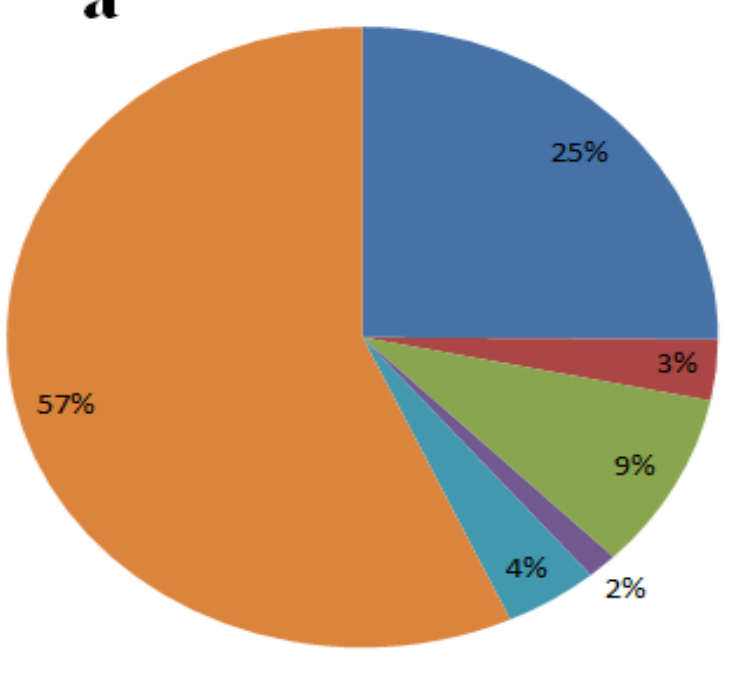

$\because \mathrm{C} \equiv \mathbf{R E} \equiv \mathbf{T}=\mathbf{H E}=\mathbf{L S}=\mathbf{H S}$

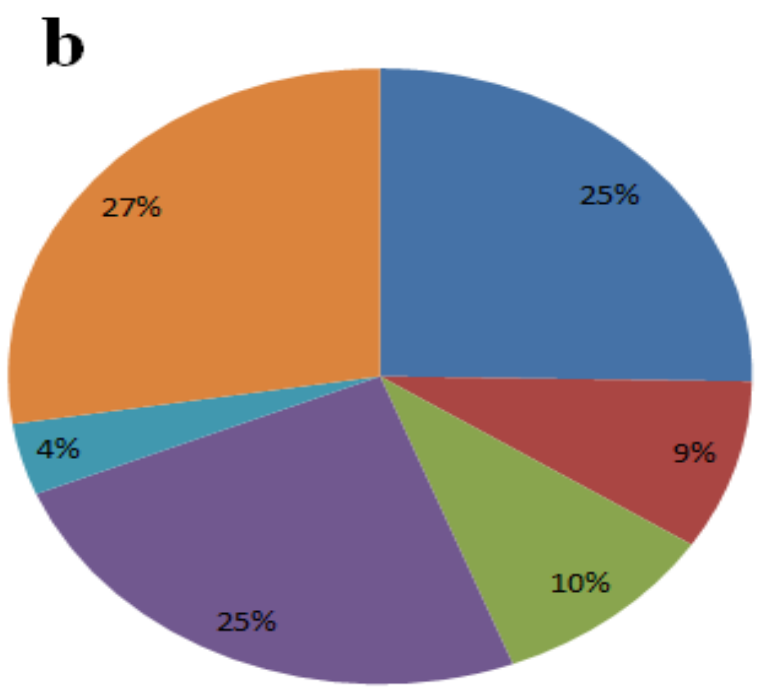

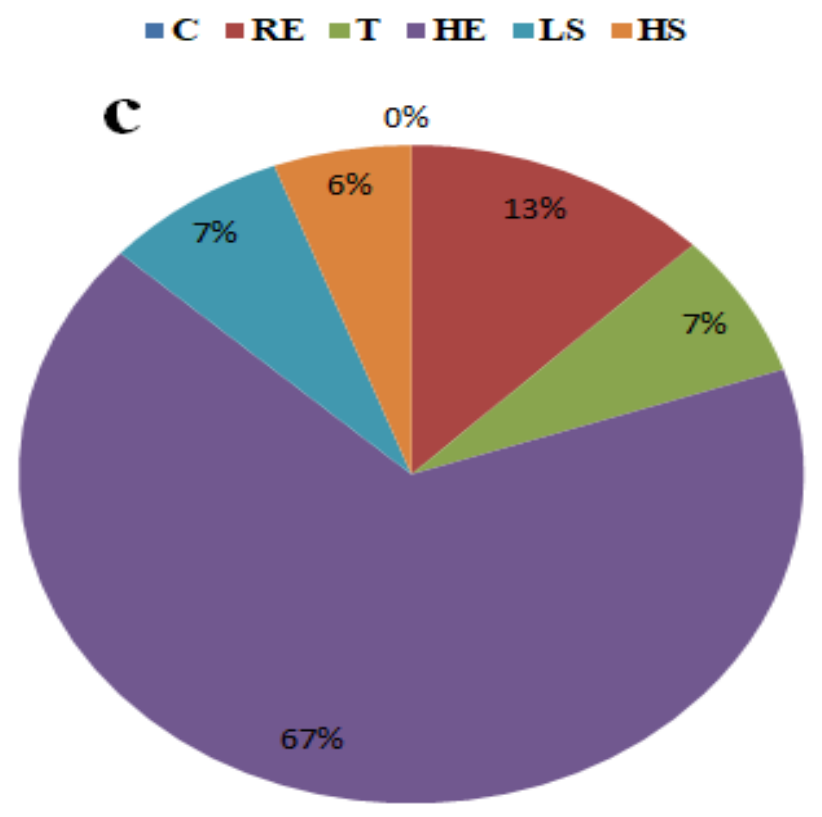

It can be seen from Figure 4 that for TC- $\mathrm{CO}_{2} \mathrm{M}$ and TC-Air, maximum irreversibility of $53.08 \%$ and $29.28 \%$, respectively, takes place in high pressure reservoir compared to the maximum of $61.79 \%$ in the heater for $\mathrm{TC}-\mathrm{CO}_{2}$. It is noteworthy to see that the irreversibility for TC- $\mathrm{CO}_{2} \mathrm{M}$ is at its minimum value for the heater in case of $\mathrm{TC}-\mathrm{CO}_{2} \mathrm{M}(1.28 \%)$, whereas, it is maximum for $\mathrm{TC}-\mathrm{CO}_{2}(61.79 \%)$. Moreover, the second maximum energy destruction in case of $\mathrm{TC}-\mathrm{CO}_{2} \mathrm{M}(2.95 \%)$ and TC-Air $(9.53 \%)$ takes place in the recuperator compared to $\mathrm{TC}_{-} \mathrm{CO}_{2}(7.03 \%)$ in the compressor and the low-pressure reservoir .

On the other hand, the minimum values were evaluated as $1.28 \%$ for the heater for $\mathrm{TC}-\mathrm{CO}_{2} \mathrm{M}, 4.01 \%$ for the low pressure reservoir for TC-Air, and $6.56 \%$ for turbine in case of $\mathrm{TC}-\mathrm{CO}_{2}$. 


\section{DOI: $10.17148 /$ IARJSET.2021.8205}

\section{ii.Sensitivity analysis of key thermodynamic parameters}

It has already been demonstrated that the $\mathrm{TC}-\mathrm{CO}_{2}$ performs better using two saline aquifers . However, when the results were compared with $\mathrm{TC}-\mathrm{CO}_{2} \mathrm{M}$, the latter outperformed the former using the same saline storage system. As mentioned in the earlier study that the energy storage pressure, release pressure and the pressure of the low pressure reservoir are primarily considered for the performance evaluation of such storage systems. Hence, a parametric analysis was conducted in this research at various pressure intensities; the pressure values for each system were kept same as (Table 6 ) for comparison. It should be noted that the discrete values of Liu's results were not given in the form of a table and close approximation from the graph were achieved using scientific image measurement software GetData Graph Digitizer; these values are presented here.

Table 6: Pressure values for parametric study

\begin{tabular}{lc}
\hline Parameter & Pressure range (MPa) \\
\hline Energy storage pressure & $40-56$ \\
Energy releasing pressure & $10-26$ \\
Pressure of low-pressure reservoir & $2-10$ \\
\hline
\end{tabular}

a. $\quad$ Effect of the energy storage pressure

The effects of energy storage pressure on the round trip efficiency and exergy efficiency is presented in Figure 5 and Table 7.

\section{Round-trip efficiency}

The round-trip efficiency of TC- $\mathrm{CO}_{2}$ slightly increases with the increase in the pressure (Figure 5a). Unlike TC-CO efficiency decreases for TC- $\mathrm{CO}_{2} \mathrm{M}$ and TC-Air. Comparing TC-Air with TC- $\mathrm{CO}_{2}$, it can be seen that the efficiency of the former was higher at $4 \mathrm{MPa}$. However, it became almost equal to each other at the pressure of $42 \mathrm{MPa}$. Finally, at 56 $\mathrm{MPa}$, the efficiency difference between TC-Air and $\mathrm{TC}-\mathrm{CO}_{2}$ was about $5 \%$ with $59.31 \%$ and $64.3 \%$ efficiency values, respectively.

In contrast, the comparison between TC- $\mathrm{CO}_{2} \mathrm{M}$ and $\mathrm{TC}-\mathrm{CO}_{2}$ showed that although the efficiency of former decreased with the increasing pressure, its values were higher at each pressure value compared to the latter one. For instance, at 40 $\mathrm{MPa}$ the round-trip efficiency of $\mathrm{TC}-\mathrm{CO}_{2} \mathrm{M}$ and $\mathrm{TC}-\mathrm{CO}_{2}$ were over $78 \%$ and $63 \%$, respectively, and at $56 \mathrm{MPa}$ were about $73 \%$ and $64 \%$, respectively. This minor difference in the percentage for $\mathrm{TC}-\mathrm{CO}_{2}$ could be due to the software convergence issues as a general-purpose software (Energy Equation Solver) has been used. This can be mitigated by developing a dedicated software to compensate for these minor differences.

The results indicated that the round-trip efficiency of the modified system was much higher than that of unmodified system using the same working fluid i.e. trans critical carbon dioxide.. The values in Figure 4 and Table 5 are given at the pressure value of $40 \mathrm{MPa}$.

The parameters shown in the tables below are T: Temperature in K, P: Pressure in MPa, h: Enthalpy in kJ/kg, s: Entropy in $\mathrm{Kj} / \mathrm{kg} . \mathrm{K}$ and e: Exergy in $\mathrm{kJ} / \mathrm{kg}$

Table 2: Thermodynamic data for the material streams of the TC-Air

\begin{tabular}{ccccccc}
\hline Stream & Material Stream & $\mathrm{T}(\mathrm{K})$ & $\mathrm{P}(\mathrm{MPa})$ & $\mathrm{h}(\mathrm{kJ} / \mathrm{kg})$ & $\mathrm{s}(\mathrm{kJ} / \mathrm{kg} \cdot \mathrm{K})$ & $\mathrm{e}(\mathrm{kJ} / \mathrm{kg})$ \\
\hline 1 & Air & 293.5 & 1.50 & 290.5 & 6.061 & 238.4 \\
2 & Air & 420.6 & 4.488 & 418.5 & 6.108 & 352.1 \\
3 & Air & 313.0 & 4.488 & 304.8 & 5.795 & 334.5 \\
4 & Air & 448.5 & 13.43 & 443.9 & 5.843 & 459.1 \\
5 & Air & 313.0 & 13.43 & 290.9 & 5.436 & 431.2 \\
6 & Air & 445.1 & 40.18 & 441.4 & 5.488 & 565.9 \\
7 & Air & 373.7 & 20.00 & 357.3 & 5.510 & 474.7 \\
8 & Air & 535.7 & 20.00 & 539.7 & 5.915 & 532.6 \\
9 & Air & 479.3 & 12.62 & 477.8 & 5.934 & 464.7 \\
10 & Air & 873.0 & 12.62 & 911.1 & 6.591 & 695.6 \\
11 & Air & 579.2 & 2.00 & 585.6 & 6.679 & 343.1 \\
12 & Air & 403.7 & 2.00 & 403.1 & 6.304 & 276.1 \\
\hline
\end{tabular}

Table 3: Thermodynamic data for the material streams of the TC- $\mathrm{CO}_{2} \mathrm{M}$

\begin{tabular}{ccccccc}
\hline Stream & Material Stream & $\mathrm{T}(\mathrm{K})$ & $\mathrm{P}(\mathrm{MPa})$ & $\mathrm{h}(\mathrm{kJ} / \mathrm{kg})$ & $\mathrm{s}(\mathrm{kJ} / \mathrm{kg} \cdot \mathrm{K})$ & $\mathrm{e}(\mathrm{kJ} / \mathrm{kg})$ \\
\hline 1 & $\mathrm{CO}_{2}$ & 308.1 & 1.50 & 501.5 & 2.226 & 153.1 \\
2 & $\mathrm{CO}_{2}$ & 405.4 & 4.488 & 580.0 & 2.256 & 222.5 \\
3 & $\mathrm{CO}_{2}$ & 385.4 & 4.488 & 558.4 & 2.201 & 217.8 \\
4 & $\mathrm{CO}_{2}$ & 313.0 & 4.488 & 473.8 & 1.957 & 208.3 \\
5 & $\mathrm{CO}_{2}$ & 413.7 & 13.43 & 541.3 & 1.982 & 268.3
\end{tabular}


International Advanced Research Journal in Science, Engineering and Technology

Vol. 8, Issue 2, February 2021

DOI: $10.17148 /$ IARJSET.2021.8205

\begin{tabular}{ccccccc}
6 & $\mathrm{CO}_{2}$ & 394.7 & 13.43 & 512.7 & 1.911 & 261.5 \\
7 & $\mathrm{CO}_{2}$ & 313.0 & 13.43 & 289.6 & 1.266 & 237.0 \\
8 & $\mathrm{CO}_{2}$ & 345.9 & 40.18 & 328.3 & 1.283 & 270.6 \\
9 & $\mathrm{CO}_{2}$ & 359.9 & 40.18 & 354.2 & 1.356 & 273.9 \\
10 & $\mathrm{CO}_{2}$ & 371.6 & 40.18 & 375.8 & 1.415 & 277.3 \\
11 & $\mathrm{CO}_{2}$ & 387.2 & 40.18 & 404.5 & 1.491 & 282.6 \\
12 & $\mathrm{CO}_{2}$ & 408.0 & 20.00 & 497.3 & 1.817 & 274.8 \\
13 & $\mathrm{CO}_{2}$ & 714.1 & 20.00 & 900.7 & 2.566 & 447.7 \\
14 & $\mathrm{CO}_{2}$ & 631.3 & 9.283 & 816.7 & 2.586 & 357.5 \\
15 & $\mathrm{CO}_{2}$ & 873.0 & 9.283 & 1104 & 2.971 & 526.3 \\
16 & $\mathrm{CO}_{2}$ & 782.4 & 4.309 & 1000 & 2.991 & 415.8 \\
17 & $\mathrm{CO}_{2}$ & 873.0 & 4.309 & 1108 & 3.122 & 483.6 \\
18 & $\mathrm{CO}_{2}$ & 783.8 & 2.00 & 1004 & 3.142 & 373.5 \\
19 & $\mathrm{CO}_{2}$ & 413.0 & 2.00 & 600.5 & 2.451 & 183.0 \\
20 & $\mathrm{CO}_{2}$ & 387.0 & 2.00 & 574.6 & 2.386 & 177.0 \\
21 & $\mathrm{CO}_{2}$ & 320.1 & 2.00 & 508.6 & 2.199 & 168.7 \\
22 & $\mathrm{CO}_{2}$ & 313.0 & 2.00 & 501.5 & 2.176 & 168.5 \\
\hline
\end{tabular}

Table 4: Results of fluid streams of TC- $\mathrm{CO}_{2} \mathrm{M}$, TC-Air and $\mathrm{TC}-\mathrm{CO}_{2}$

\begin{tabular}{|c|c|c|c|c|}
\hline Term & Unit & $\mathrm{TC}-\mathrm{CO}_{2} \mathrm{M}$ & TC-Air & $\mathrm{TC}-\mathrm{CO}_{2}[21]$ \\
\hline C1 Power & $\mathrm{kJ} / \mathrm{kg}$ & 78.5 & 128.0 & 78.4 \\
\hline C2 Power & $\mathrm{kJ} / \mathrm{kg}$ & 67.5 & 139.1 & 67.5 \\
\hline C3 Power & $\mathrm{kJ} / \mathrm{kg}$ & 38.7 & 150.6 & 38.5 \\
\hline T1 Power & $\mathrm{kJ} / \mathrm{kg}$ & 84.0 & 61.9 & 103.6 \\
\hline T2 Power & $\mathrm{kJ} / \mathrm{kg}$ & 104.4 & 325.6 & 151.2 \\
\hline T3 Power & $\mathrm{kJ} / \mathrm{kg}$ & 103.9 & NA & NA \\
\hline Thermal input 1 & $\mathrm{~kJ} / \mathrm{kg}$ & 287.4 & 433.3 & 457.7 \\
\hline Thermal input 2 & $\mathrm{~kJ} / \mathrm{kg}$ & 108.1 & NA & NA \\
\hline Round trip efficacy & $\%$ & 78.43 & 52.34 & 63.4 \\
\hline Exergy efficiency & $\%$ & 89.72 & 85.82 & 53.0 \\
\hline
\end{tabular}

Table 5: Exergy destructction ratio of each component

\begin{tabular}{lccc}
\hline Component & $\mathrm{TC}-\mathrm{CO}_{2} \mathrm{M}$ & $\mathrm{TC}-$ Air & $\mathrm{TC}-\mathrm{CO}_{2}[21]$ \\
\hline Compressor & $23.46 \%$ & $26.92 \%$ & $7.03 \%$ \\
Recuperator & $2.95 \%$ & $9.53 \%$ & $11.77 \%$ \\
Turbine & $8.65 \%$ & $10.64 \%$ & $6.56 \%$ \\
Heater & $1.28 \%$ & $26.19 \%$ & $61.79 \%$ \\
Low pressure reservoir & $3.99 \%$ & $4.01 \%$ & $7.03 \%$ \\
High pressure reservoir & $53.08 \%$ & $29.28 \%$ & $5.25 \%$ \\
\hline
\end{tabular}


International Advanced Research Journal in Science, Engineering and Technology

Vol. 8, Issue 2, February 2021

DOI: $10.17148 /$ IARJSET.2021.8205

$\square \mathrm{C} \backsim \mathrm{RE} \sim \mathrm{T} \backsim \mathrm{HE} \backsim \mathrm{LS} \sim \mathrm{HS}$

$\mathbf{a}$

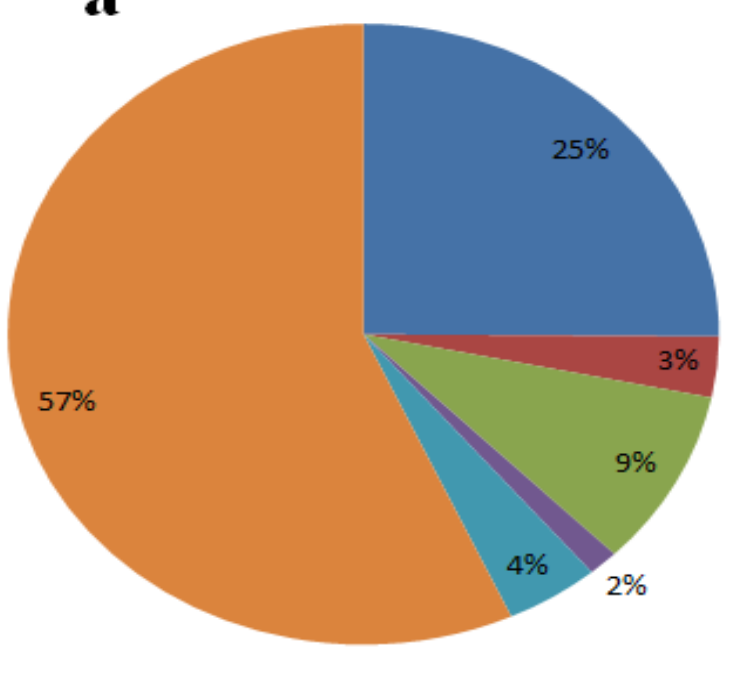

$\because \mathrm{C} \square \mathrm{RE} \backsim \mathrm{T} \square \mathrm{HE}=\mathrm{LS} \backsim \mathrm{HS}$

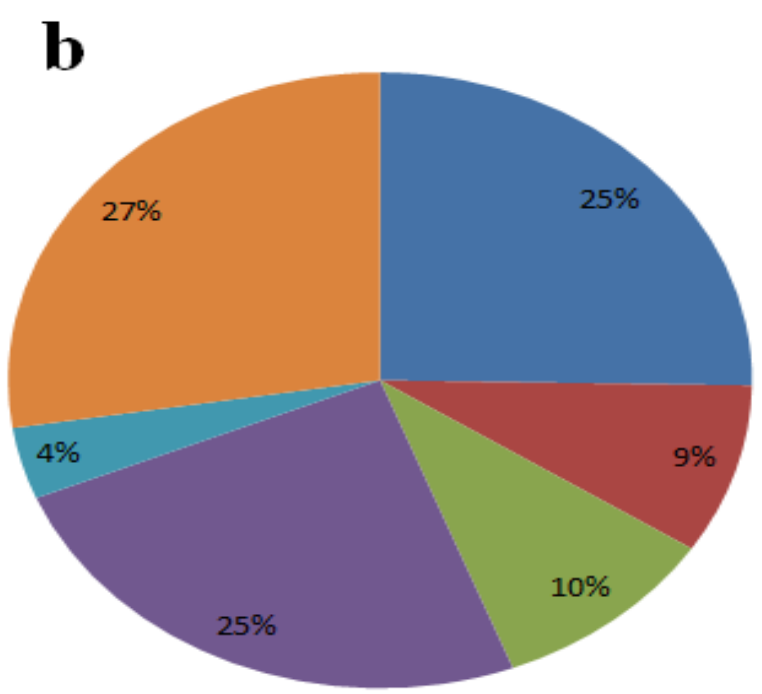

$\because \mathrm{C} \square \mathrm{RE} \backsim \mathrm{T} \backsim \mathrm{HE}=\mathrm{LS}=\mathrm{HS}$

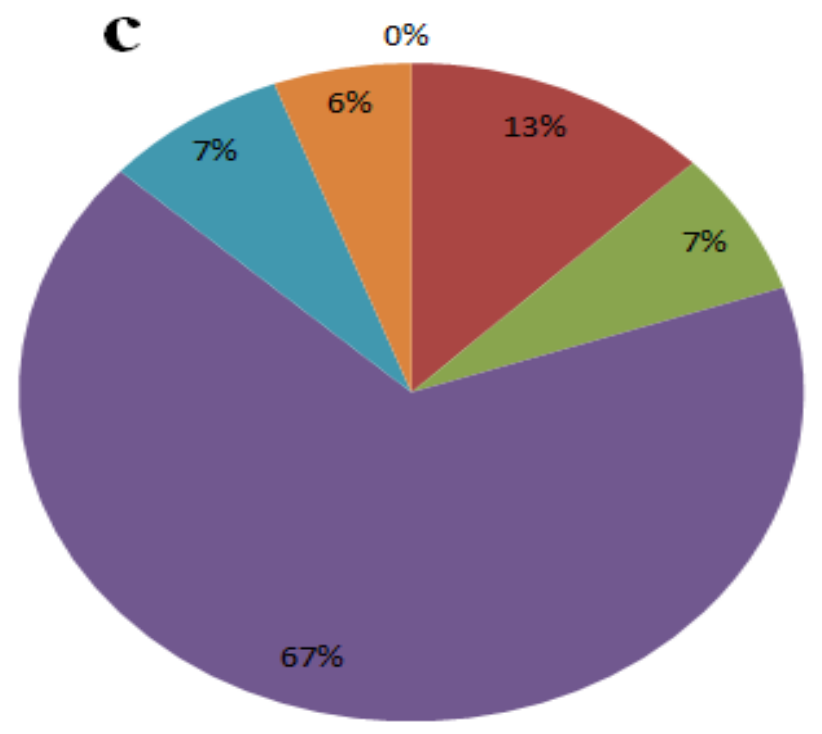

Figure 4: Exergy destruction ratio at $40 \mathrm{MPa}$

a) TC-CO2M, b) TC-Air and c) TC-CO2 [21]

$\mathrm{C}=$ Compressor, $\mathrm{RE}=$ Recuperator, $\mathrm{T}=$ Turbine, $\mathrm{HE}=$ Heater, $\mathrm{LS}=$ low pressure reservoir and HS=High pressure reservoir

It can be seen from Figure 4 that for TC- $\mathrm{CO}_{2} \mathrm{M}$ and TC-Air, maximum irreversibility of $53.08 \%$ and $29.28 \%$, respectively,

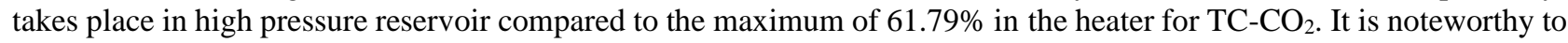
see that the irreversibility for TC- $\mathrm{CO}_{2} \mathrm{M}$ is at its minimum value for the heater in case of $\mathrm{TC}-\mathrm{CO}_{2} \mathrm{M}(1.28 \%)$, whereas, it is maximum for $\mathrm{TC}-\mathrm{CO}_{2}(61.79 \%)$. Moreover, the second maximum energy destruction in case of $\mathrm{TC}-\mathrm{CO}_{2} \mathrm{M}(2.95 \%)$ and TC-Air (9.53\%) takes place in the recuperator compared to $\mathrm{TC}-\mathrm{CO}_{2}(7.03 \%)$ in the compressor and the low-pressure reservoir .

On the other hand, the minimum values were evaluated as $1.28 \%$ for the heater for $\mathrm{TC}-\mathrm{CO}_{2} \mathrm{M}, 4.01 \%$ for the low pressure reservoir for TC-Air, and $6.56 \%$ for turbine in case of $\mathrm{TC}-\mathrm{CO}_{2}$.

\section{iii.Sensitivity analysis of key thermodynamic parameters}

It has already been demonstrated that the $\mathrm{TC}-\mathrm{CO}_{2}$ performs better using two saline aquifers [21]. However, when the results were compared with $\mathrm{TC}-\mathrm{CO}_{2} \mathrm{M}$, the latter outperformed the former using the same saline storage system. As mentioned in the earlier study that the energy storage pressure, release pressure and the pressure of the low pressure 


\section{DOI: $10.17148 /$ IARJSET.2021.8205}

reservoir are primarily considered for the performance evaluation of such storage systems [21]. Hence, a parametric analysis was conducted in this research at various pressure intensities; the pressure values for each system were kept same as [21] (Table 6) for comparison. It should be noted that the discrete values of Liu's [21] results were not given in the form of a table and close approximation from the graph were achieved using scientific image measurement software GetData Graph Digitizer [3]; these values are presented here.

Table 6: Pressure values for parametric study

\begin{tabular}{cc}
\hline Parameter & Pressure range (MPa) \\
\hline Energy storage pressure & $40-56$ \\
Energy releasing pressure & $10-26$ \\
Pressure of low-pressure reservoir & $2-10$ \\
\hline $\boldsymbol{b} . \quad$ Effect of the energy storage pressure
\end{tabular}

The effects of energy storage pressure on the round trip efficiency and exergy efficiency is presented in Figure 5 and Table 7.

\section{Round-trip efficiency}

The round-trip efficiency of TC- $\mathrm{CO}_{2}$ slightly increases with the increase in the pressure (Figure 5a). Unlike TC-CO 2 , the efficiency decreases for TC- $\mathrm{CO}_{2} \mathrm{M}$ and TC-Air. Comparing TC-Air with $\mathrm{TC}-\mathrm{CO}_{2}$, it can be seen that the efficiency of the former was higher at $4 \mathrm{MPa}$. However, it became almost equal to each other at the pressure of $42 \mathrm{MPa}$. Finally, at 56 $\mathrm{MPa}$, the efficiency difference between TC-Air and $\mathrm{TC}-\mathrm{CO}_{2}$ was about $5 \%$ with $59.31 \%$ and $64.3 \%$ efficiency values, respectively.

In contrast, the comparison between TC- $\mathrm{CO}_{2} \mathrm{M}$ and $\mathrm{TC}-\mathrm{CO}_{2}$ showed that although the efficiency of former decreased with the increasing pressure, its values were higher at each pressure value compared to the latter one. For instance, at 40 $\mathrm{MPa}$ the round-trip efficiency of $\mathrm{TC}-\mathrm{CO}_{2} \mathrm{M}$ and $\mathrm{TC}-\mathrm{CO}_{2}$ were over $78 \%$ and $63 \%$, respectively, and at $56 \mathrm{MPa}$ were about $73 \%$ and $64 \%$, respectively. This minor difference in the percentage for $\mathrm{TC}-\mathrm{CO}_{2}$ could be due to the software convergence issues as a general-purpose software (Energy Equation Solver) has been used. This can be mitigated by developing a dedicated software to compensate for these minor differences.

The results indicated that the round-trip efficiency of the modified system was much higher than that of unmodified system using the same working fluid i.e. trans critical carbon dioxide.

Table 7: Storage pressure - pressure $v s$. efficiencies

\begin{tabular}{ccccrrr}
\hline $\begin{array}{l}\text { Pressure value } \\
\text { (MPa) }\end{array}$ & \multicolumn{3}{c}{ Round -trip efficiency } & \multicolumn{2}{c}{ Exergy efficiency } \\
& $\begin{array}{c}\text { TC- } \\
\text { CO2M }\end{array}$ & TC-Air & TC-CO2 [21] & TC-CO2M & TC-Air & TC-CO2 [21] \\
\hline 40 & 78.43 & 64.91 & 63.4 & 89.72 & 86.35 & 53.1 \\
42 & 77.69 & 64.08 & 63.6 & 89.6 & 86.14 & 53.2 \\
44 & 76.97 & 63.29 & 63.8 & 89.49 & 85.95 & 53.3 \\
46 & 76.29 & 62.54 & 64.1 & 89.39 & 85.76 & 53.5 \\
48 & 75.63 & 61.84 & 64.2 & 89.28 & 85.58 & 53.6 \\
50 & 75.12 & 61.16 & 64.3 & 89.18 & 85.4 & 53.7 \\
52 & 74.39 & 60.52 & 64.2 & 89.08 & 85.23 & 53.8 \\
54 & 73.81 & 59.91 & 64.3 & 88.98 & 85.07 & 53.8 \\
56 & 73.23 & 59.31 & 64.3 & 88.89 & 84.92 & 53.9 \\
\hline
\end{tabular}
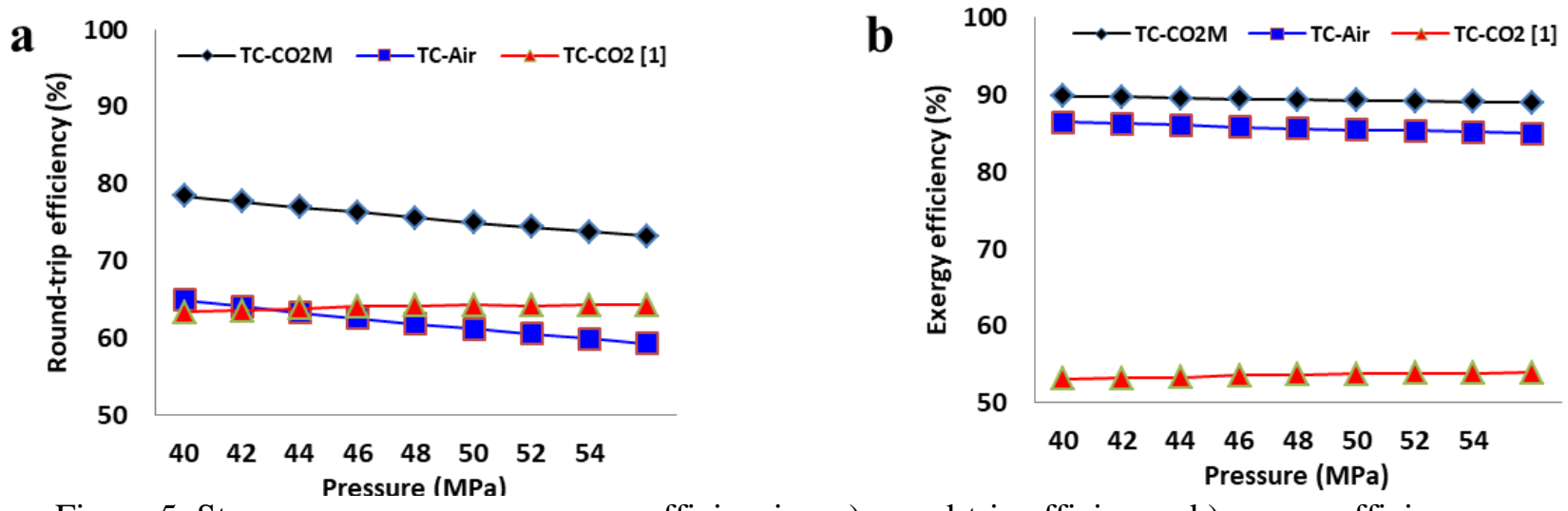

Figure 5: Storage pressure - pressure vs. efficiencies: a) round-trip efficiency, b) exergy efficiency 


\section{DOI: $10.17148 /$ IARJSET.2021.8205}

\section{Exergy efficiency}

Figure 5b shows the effect of energy storage pressure on the exergy efficiency. A similar trend was observed for all of the three working fluids. The exergy efficiency of $\mathrm{TC}-\mathrm{CO}_{2} \mathrm{M}$ and TC-Air was higher than TC- $\mathrm{CO}_{2}$. The change in pressure of storage pressure has no noticeable effect on the exergy efficiency. Furthermore, an increased exergy efficiency over $35 \%$ was noticed in case of $\mathrm{TC}-\mathrm{CO}_{2} \mathrm{M}$ compared to $\mathrm{TC}-\mathrm{CO}_{2}$.

As seen in figures $5 \mathrm{a}$ and $5 \mathrm{~b}$, increasing the pressure of the high-pressure reservoir has an unfavorable effect on both efficiencies. The reason for this is that the high-pressure reservoir depends on the outlet pressure of last compression stage. Hence if the outlet pressure of the compressor increases, this physically means that more mechanical work is being added to produce the increasing of pressure and this reduces the efficiency of the entire process.

The difference between results presented for TC-CO2 in figures $5 \mathrm{a}$ and $5 \mathrm{~b}$ is due to the fact that in [21] the author uses a different software (Coolprop) to extract the properties of the fluids. Also, the author's exergy efficiency calculations did not take into consideration the exergy destroyed in some equipment like pre-coolers and inner coolers. The discrepancy seen between the range of values of figures $5 \mathrm{a}$ and $5 \mathrm{~b}$ is due to the relationships expressed in both variables. Round trip efficiency is related to the energy recovered in the form of electricity in the case of use of natural gas as fuel. On the other hand, exergy efficiency represents the energy recovered in the form of electricity due to heat absorbed from the reservoirs.

\section{Exergy destruction rate}

Figure 6 presents the effect of storage pressure on exergy destruction rate. It can be seen that the maximum magnitude for exergy destruction rate in any system-component was observed at the heater in case of $\mathrm{TC}^{-\mathrm{CO}_{2}}$ [21]. The value of destruction rate also increased with the increase in pressure. Unlike for the heater, for all other components, the value decreased with the increase in pressure. However, in the case of TC-Air and $\mathrm{TC}-\mathrm{CO}_{2} \mathrm{M}$, the exergy destruction rate increased for high pressure reservoir only. It remained almost constant for all of the other components for TC-Air and $\mathrm{TC}-\mathrm{CO}_{2} \mathrm{M}$.
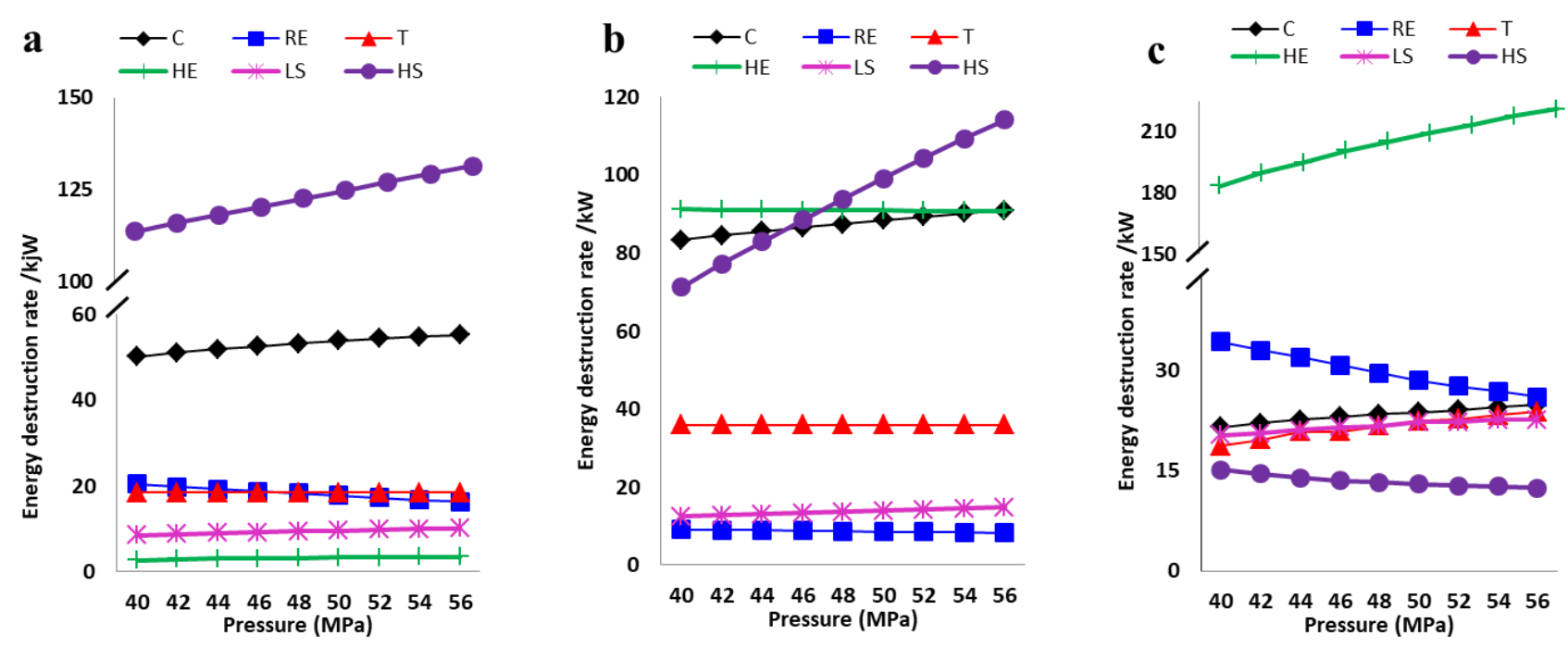

Figure 6: Effect of energy storage pressure on exergy destruction rate

a) $\mathrm{TC}-\mathrm{CO}_{2} \mathrm{M}$, b) TC-Air and c) TC- $\mathrm{CO}_{2}[21]$

$\mathrm{C}=$ compressor, $\mathrm{RE}=$ recuperator, $\mathrm{T}=$ turbine, $\mathrm{HE}=$ heater, $\mathrm{LS}=\mathrm{low}$ pressure reservoir and $\mathrm{HS}=$ high pressure reservoir

\section{c. $\quad$ Effect of the energy releasing pressure}

\section{Round-trip efficiency}

The round-trip efficiency of TC- $\mathrm{CO}_{2} \mathrm{M}$ is higher at each pressure value compared to the other two working fluids (see Figure 7a). Further comparison between TC-Air and TC- $\mathrm{CO}_{2}$ shows that the efficiency of both fluids showed almost a similar trend with a slight difference in the magnitude. However, the round-trip efficiency of $\mathrm{TC}^{-} \mathrm{CO}_{2} \mathrm{M}$ was higher than TC-Air and TC- $\mathrm{CO}_{2}$ by $\sim 15 \%$. For instance, at $10 \mathrm{MPa}, \mathrm{TC}-\mathrm{CO}_{2} \mathrm{M}$ has just over $63 \%$ efficiency compared to $\sim 56 \%$ of TC- $\mathrm{CO}_{2}$, and at $26 \mathrm{MPa}$ it was $82 \%$ and $65.5 \%$, respectively. This indicated that the modified system can not only perform better than unmodified system using trans critical carbon dioxide but also the efficiency difference between modified and unmodified system also increases with the increase in pressure 
International Advanced Research Journal in Science, Engineering and Technology

Vol. 8, Issue 2, February 2021

DOI: $10.17148 /$ IARJSET.2021.8205

Table 8: Releasing pressure - pressure vs. efficiencies

\begin{tabular}{lccccccc}
\hline $\begin{array}{l}\text { Pressure value } \\
\text { (MPa) }\end{array}$ & \multicolumn{3}{c}{ Round trip efficiency } & \multicolumn{3}{c}{ Exergy efficiency } \\
\hline 10 & TC-CO2M & TC-Air & TC-CO2 [21] & & TC-CO2M & TC-Air & TC-CO2 [21] \\
12 & 63.28 & 50.65 & 55.9 & & 88.14 & 83.62 & 47.8 \\
14 & 68.31 & 54.05 & 58.1 & & 88.65 & 84.26 & 49.3 \\
16 & 71.86 & 56.69 & 59.8 & & 89.02 & 84.76 & 50.6 \\
18 & 74.55 & 58.81 & 61.3 & 89.29 & & 85.17 & 51.4 \\
20 & 76.65 & 60.58 & 62.3 & 89.52 & & 85.51 & 52.3 \\
22 & 78.36 & 62.09 & 63.2 & 89.71 & & 85.81 & 53.1 \\
24 & 79.81 & 63.41 & 64.1 & 89.87 & & 86.05 & 53.5 \\
26 & 81.02 & 64.56 & 64.8 & 90.02 & & 86.28 & 53.9 \\
\hline
\end{tabular}
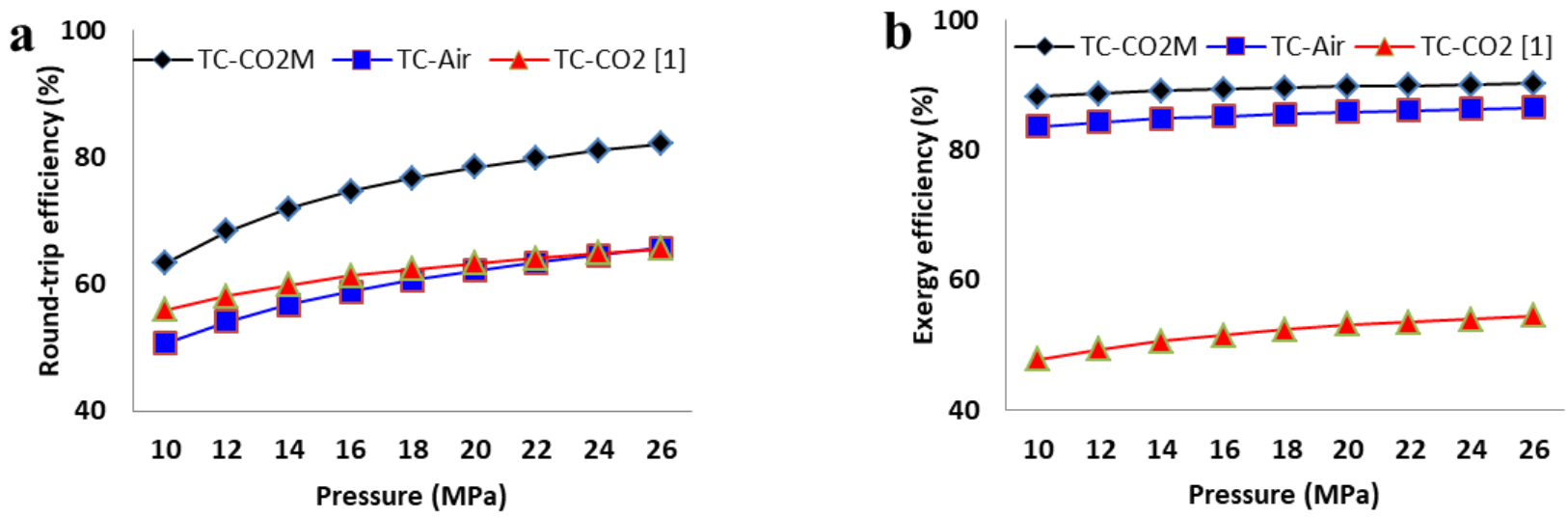

Figure 7: Releasing pressure - pressure vs. efficiencies: a) round-trip efficiency, b) exergy efficiency

\section{Exergy efficiency}

Figure $7 \mathrm{~b}$ shows the effect of releasing pressure on the exergy efficiency. A similar trend was observed for all of the three working fluids. The exergy efficiency of TC- $\mathrm{CO}_{2} \mathrm{M}$ and $\mathrm{TC}$-Air was higher than that of $\mathrm{TC}-\mathrm{CO}_{2}$ by a significant amount; even higher than that was observed in round-trip case. It can be seen that at $10 \mathrm{MPa}$, the exergy efficiency difference between $\mathrm{TC}-\mathrm{CO}_{2} \mathrm{M}$ and $\mathrm{TC}-\mathrm{CO}_{2}$ was about $40 \%$ compared to $36 \%$ at $26 \mathrm{MPa}$. Nevertheless, the efficiency values appeared to become constant at about $24 \mathrm{MPa}$ value. This could indicate that increasing the pressure value would not affect the exergy efficiency of the systems/fluids.

As seen in figures $7 \mathrm{a}$ and $7 \mathrm{~b}$ increasing the releasing pressure of the reservoir has a favorable effect for the entire process. The reason is that the releasing pressure is modeled using a valve, which is a device that creates entropy. Therefore, as the releasing pressure increases, it becomes similar to the storage pressure. The entropy generated is reduced and exergy efficiency increases. Another reason for the behavior seen is that after the high storage pressure reservoir, the fluid is further sent to turbines which are devices that recover mechanical work from fluids with high energetic content. Higher pressure physically means higher energetic content. This allows for recovering more energy and hence enhancing the efficiency of the process. The difference between results presented for TC-CO2 in figures $7 \mathrm{a}$ and $7 \mathrm{~b}$ can also be explained using the same reasoning used for the difference between figures $5 \mathrm{a}$ and $5 \mathrm{~b}$.

\section{Exergy destruction rate}

It can be seen from Figure 8 that the behaviour of exergy destruction with respect to the increasing pressure was almost similar in the two cases of TC- $\mathrm{CO}_{2}$ and TC-Air. The destruction rate for heater increases with the increase in pressure and it decreases for the high pressure reservoir. As for the compressor, it remains the same.

Compared to TC- $\mathrm{CO}_{2}$ and TC-Air, TC- $\mathrm{CO}_{2} \mathrm{M}$ behaved in a different manner. It appeared that the change in pressure had no effect on the exergy destruction rate for any of the components. The exergy destruction rate magnitude was higher for the high-pressure reservoir $(114 / \mathrm{kW})$ followed by the compressor $(50 / \mathrm{kW})$ and all of the other components had a magnitude lower than $/ 20 \mathrm{~kW}$.

It can be observed from the figure that the recuperator, low pressure reservoir and turbine have performed in the same manner for $\mathrm{TC}-\mathrm{CO}_{2} \mathrm{M}, \mathrm{TC}-\mathrm{CO}_{2}$ and TC-Air, with exergy destruction rate slightly changed and nearly below 30/kW. 

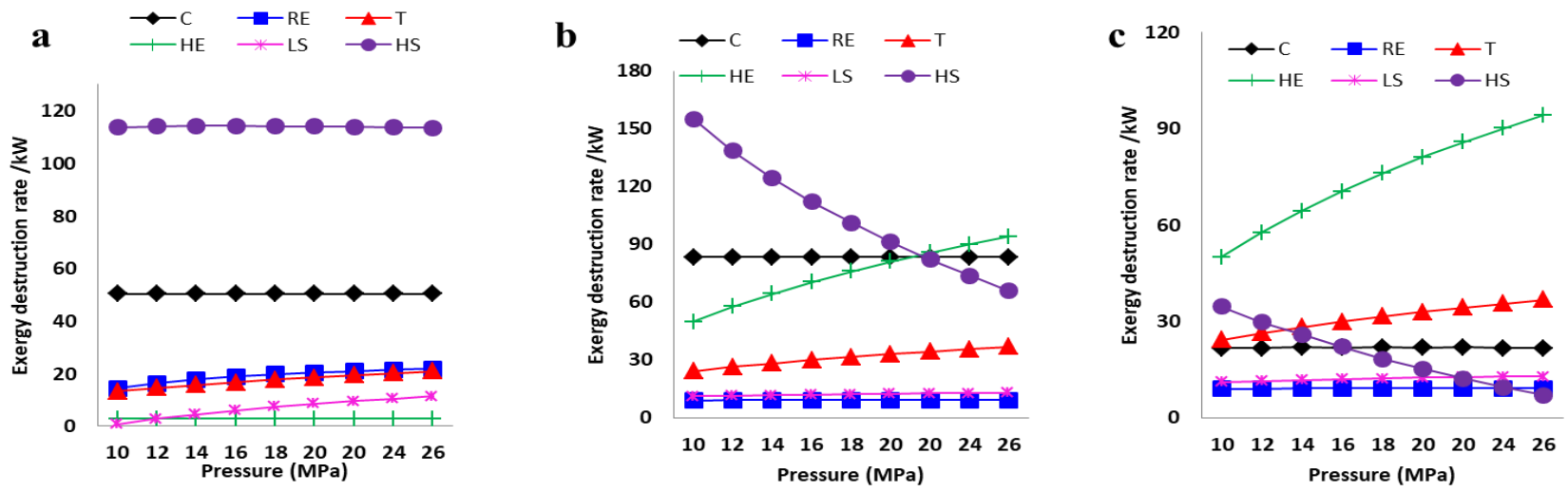

Figure 8: Effect of energy releasing pressure on exergy destruction rate

a) $\mathrm{TC}-\mathrm{CO}_{2} \mathrm{M}$, b) TC-Air and c) $\mathrm{TC}-\mathrm{CO}_{2}[21]$ reservoir

$\mathrm{C}=$ compressor, $\mathrm{RE}=$ recuperator, $\mathrm{T}=$ turbine, $\mathrm{HE}=$ heater, $\mathrm{LS}=$ low pressure reservoir and $\mathrm{HS}=$ high pressure

\section{d. $\quad$ Effect of pressure of low-pressure reservoir}

In this section the effect of change in pressure of low-pressure reservoir on the systems' performance is discussed. Reviewing [21] in details, it has been found that the results for trans critical carbon dioxide were not given in a direct or indirect form. It was explained, however, that the trends between trans critical carbon dioxide and supercritical carbon dioxide were similar. The system performance in terms of round trip efficiency, exergy efficiency and exergy destruction rate are given below.

\section{Round-trip efficiency}

The round trip efficiency of TC- $\mathrm{CO}_{2} \mathrm{M}$ is fluctuating between $78 \%$ and $85 \%$ at different pressure values (Figure $9 \mathrm{a}$ ). However, it remained above $78 \%$ for all pressure values. This trend is similar to [21] with the exception that the round efficiency fell below $50 \%$ at about $7 \mathrm{MPa}$ and increases again to about $60 \%$ at $10 \mathrm{MPa}$ [21]. This is compared with the current study where it remained above $78 \%$ at all pressure values.

Furthermore, it is clear from Figure 9a that the round-trip efficiency in case of TC-Air decreases from $63 \%$ to $54 \%$ with the increase in pressure from $2 \mathrm{MPa}$ to $10 \mathrm{MPa}$.
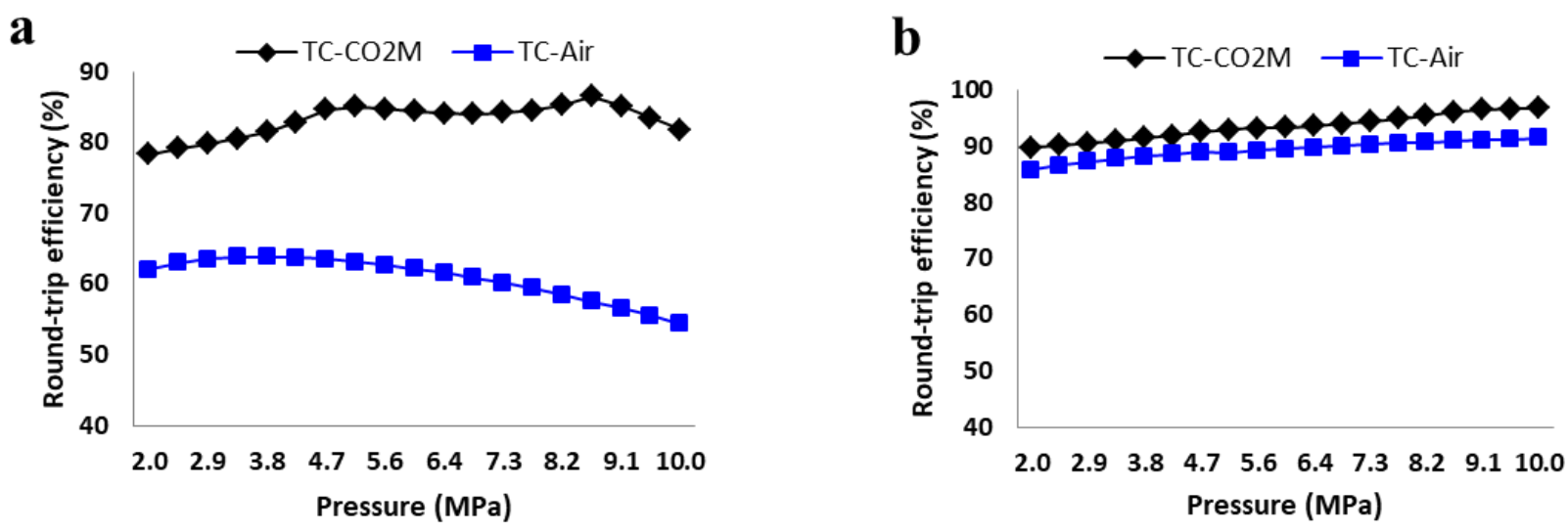

Figure 9: Low pressure reservoir - pressure vs. efficiencies: a) round-trip efficiency, b) exergy efficiency

\section{Exergy efficiency}

Exergy efficiency increases slightly with the increase in pressure of the low-pressure reservoir for both $\mathrm{TC}-\mathrm{CO}_{2} \mathrm{M}$ and TC-Air (Figure 9). The efficiency for the modified system was substantially higher than the unmodified system with a completely different trend compared to [21]: where it decreases and then increases. Moreover, the exergy efficiency drops from $54 \%$ to $35 \%$ and then increases to $55 \%$ for $2 \mathrm{MPa}, 6 \mathrm{MPa}$ and $10 \mathrm{MPa}$ pressure, respectively. When these results are compared with the current research, the modified system performed at over $90 \%$ efficiency at all pressure values of the low-pressure reservoir. This indicates that the three-stage turbine energy storage system has higher performance potential compared to the unmodified system.

To further investigate the system performance, output turbine and input compressor powers are compared (Figure 10). It can be seen that the turbine output and compressor input powers decrease with the increase in pressure of the lowpressure reservoir for TC- $\mathrm{CO}_{2} \mathrm{M}$ and TC-Air with a similar trend for both fluids. 


\section{DOI: $10.17148 / I A R J S E T .2021 .8205$}

The reduction in turbine output power is almost similar to the compressor power input. Nonetheless, the power of modified system is greater at lower pressures.

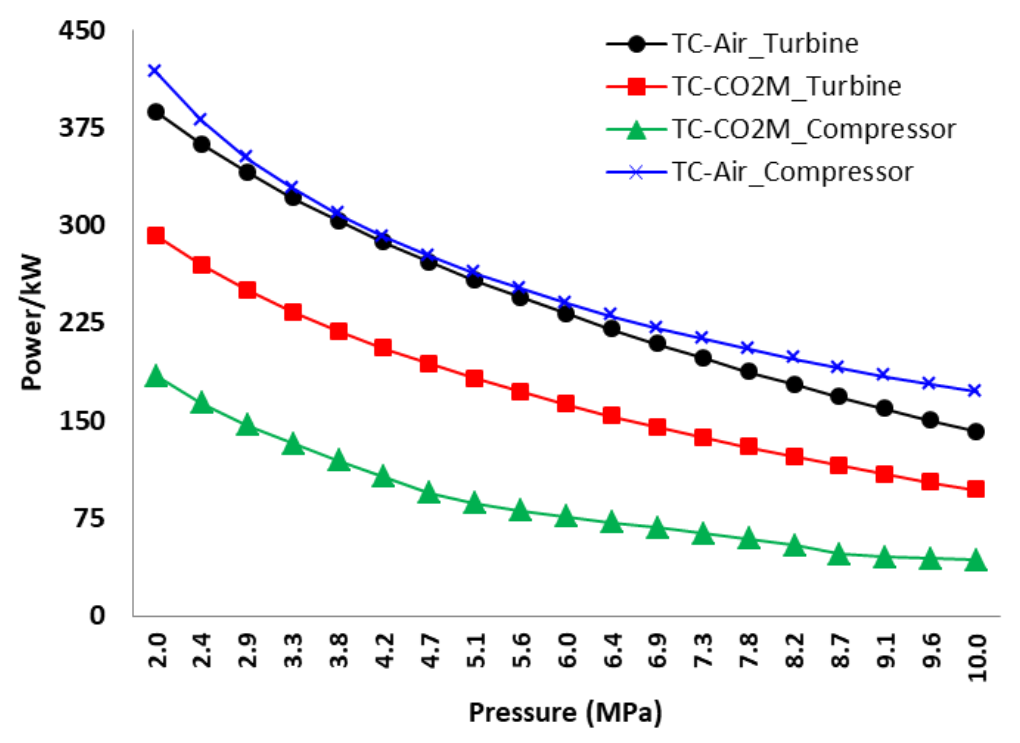

Figure 10: Power comparison - turbine output vs. compressor input

\section{Exergy destruction rate}

The effect of changing pressure of the low-pressure reservoir for TC- $\mathrm{CO}_{2} \mathrm{M}$ and TC-Air is shown in Figure 11. For TCAir except for recuperator, the exergy destruction rate decreases with the increase in pressure of the low-pressure reservoir for all of the system components such as compressor, turbine, heater, low pressure reservoir and high-pressure reservoir. In the case of the compressor, the exergy destruction decreases from $2 \mathrm{MPa}$ and suddenly increases at $5 \mathrm{MPa}$ and then started decreasing until $10 \mathrm{MPa}$.

For $\mathrm{TC}-\mathrm{CO}_{2} \mathrm{M}$, the exergy destruction remains almost unchanged with the change in pressure of the low-pressure reservoir for the recuperator, turbine and low-pressure reservoir (Figure 11a). The high-pressure reservoir showed a maximum decrease in the exergy destruction rate with respect to the pressure change: from $120 / \mathrm{kW}$ to $40 / \mathrm{kW}$ for $2 \mathrm{MPa}$ to $10 \mathrm{MPa}$ pressure values, respectively.

However, focusing on the heater, negative values were observed for the exergy destruction rate beyond a pressure of 3.8 MPa where the value becomes zero. The value then decreases to $-4.7 / \mathrm{kW}$ till $5.1 \mathrm{MPa}$ and almost remains unchanged till 6.9 MPa. The exergy decreases again from $-4.7 / \mathrm{kW}$ to $-13.75 / \mathrm{kW}$ at $8.2 \mathrm{MPa}$ and remains unchanged until the final pressure value of $10 \mathrm{MPa}$ is reached. Negative values of exergy destruction rate in heaters mean that conditions at the relative nodes cannot be reached in real life. To prevent this scenario, one possible solution would be to increase the temperature of the hot source of the heaters to allow better heat transfer in the heaters.
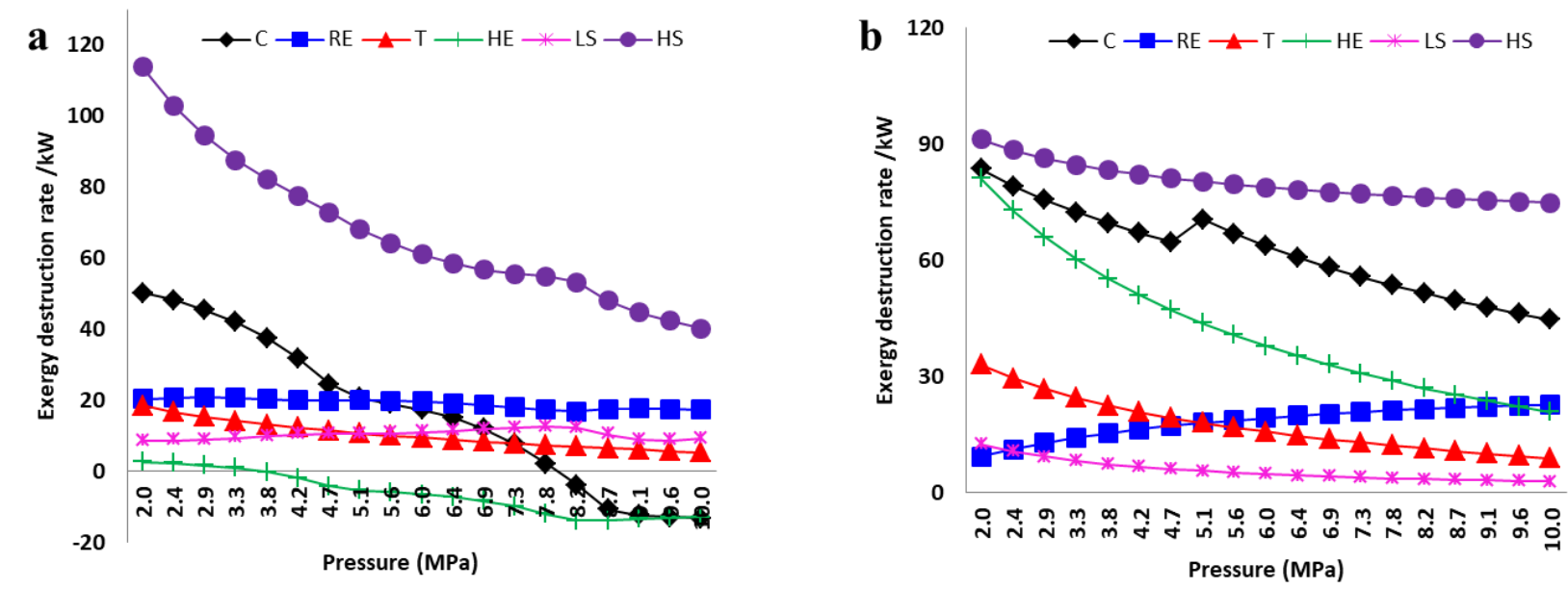

a) $\mathrm{TC}-\mathrm{CO}_{2} \mathrm{M}$, b) TC-Air

Figure 11: Effect of energy releasing pressure on exergy destruction rate

$\mathrm{C}=$ compressor, $\mathrm{RE}=$ recuperator, $\mathrm{T}=$ turbine, $\mathrm{HE}=$ heater, $\mathrm{LS}=$ low pressure reservoir and $\mathrm{HS}=$ high pressure reservoir 


\section{International Advanced Research Journal in Science, Engineering and Technology}

Vol. 8, Issue 2, February 2021

\section{DOI: $10.17148 /$ IARJSET.2021.8205}

The value selected by the EES software for this temperature was $1110 \mathrm{~K}$ and this value was kept constant. This is the reason for the negative values of exergy destruction rate for pressures higher than $4 \mathrm{MPa}$ in the high-pressure reservoirs. Due to the difficulty of increasing the temperature of the hot source, and the high cost of the construction materials needed to handle these temperatures, the most appropriate solution would be to reduce the pressure of the low-pressure reservoir. This allows the turbine to produce more mechanical work and hence reach the appropriate conditions to increase fuel exergy of the heaters, which results in positive values of exergy destruction rate.

As for the compressor, zero exergy was reached at $8 \mathrm{MPa}$ which decreases to $-11 / \mathrm{kW}$ at about $9 \mathrm{MPa}$ and remains unchanged until $10 \mathrm{MPa}$. This is not practically possible and can be explained as follows. If the pressure of low-pressure reservoir increases and the pressure-drop from throttle valve is kept constant, the inlet pressure for the first compressor will increase. As the inlet pressure for the first compressor increases, the pressure ratio of compressor will decrease and hence the temperature of streams at the corresponding nodes will also decrease. As constant values of $\Delta \mathrm{T}$ were chosen for the internal heat exchangers, negative values for exergy destruction rate mean that, the values of $\Delta \mathrm{T}$ in the internal heat exchangers cannot be reached. Therefore, the heat transfer in these heat exchangers is less than expected because there is no significant cooling of the stream to the desired level.

\section{IV.CONCLUSIONS}

The parametric analysis was conducted using Engineering Equation Solver (EES) software, and the current energy and parametric models were validated with [21] system using trans critical $\mathrm{CO}_{2}$ as a working fluid. The results were found to be in close agreement, suggesting the authenticity of the current system. Using this new proposed model, trans critical and supercritical air were studied using the current [21] system, whereas trans critical $\mathrm{CO}_{2}$ was investigated using the modified system. The modification included a third turbine, a second recuperator and heat exchangers at the outlet of the compressors. The conclusions are summarised as follows:

- $\quad$ Supercritical air cannot be used as a working fluid both in the existing and modified system. This could be due to its thermodynamic properties which are completely different due to the presence of nitrogen and oxygen in the air mixture. The analysis suggested a complete cycle is not sustainable for the supercritical air. Further experimentation could be done to understand this.

- Trans critical air performed better than supercritical air. However, the energy losses are greater than $\mathrm{CO}_{2}$, disqualifying air as a fluid in the modern energy storage systems.

- $\quad$ Trans critical $\mathrm{CO}_{2}$ performed better in all aspects compared to the air using the modified system $\left(\mathrm{TC}-\mathrm{CO}_{2} \mathrm{M}\right)$ in three major ways:

- $\quad$ the smallest values of exergy destruction rate for each of the components were achieved by $\mathrm{TC}-\mathrm{CO}_{2} \mathrm{M}$

- $\quad$ the highest values of round-trip efficiency and exergy efficiency were achieved by $\mathrm{TC}-\mathrm{CO}_{2} \mathrm{M}$

- the highest recuperation of mechanical work takes place in the case of $\mathrm{TC}-\mathrm{CO}_{2} \mathrm{M}$

All of the above-mentioned benefits, based on the results of the study, help in recovering an additional $28 \%$ of mechanical work in comparison with [21] trans critical case. This additional energy recovery can be seen as fuel saving in energy that would have created more $\mathrm{CO}_{2}$ released into the atmosphere. With the whole concept already depending on injecting $\mathrm{CO}_{2}$ underground rather than released into the atmosphere, it is a big environmental plus. However, a detailed case study at an actual power plant is advised

\section{REFERENCES}

[1] L. Barra and C. D, "Renewable energy capability to save carbon emissions," Solar Energy, vol. 57, no. 6, pp. 485-491, 1996.

[2] D. Gielen, F. Boshell, D. Saygin, M. D. Bazilian, N. Wagner and R. Gorini, "The role of renewable energy in the global energy transformation," Energy Strategy Reviews, vol. 24, pp. 38-50, 2019.

[3] G. Ren, W. Jie, J. Liu, D. Yu and L. Söder, “Analysis of wind power intermittency based on historical wind power data,” Energy, vol. 150, pp. 482492, 2018.

[4] D.-P. Reid, "Effects of wind power intermittency on generation and emissions," The Electricity Journal, vol. 32, pp. 25-30, 2019.

[5] M. Mahmoud, M. Ramadan, A.-G. P. Olabi, N. Keith and Sumsun, "A review of mechanical energy storage systems combined with wind and solar applications," Energy Conversion and Management, vol. 210, p. 112670, 2020.

[6] S. Chena, A. Arabkoohsar, T. Zhu and P. M. Nielsenb, "Development of a micro-compressed air energy storage system model based on experiments," Energy, vol. 197, p. 117152, 2020.

[7] Y. Hao, Q. He and D. Du, "A trans-critical carbon dioxide energy storage system with heat pump to recover stored heat of compression," Renewable Energy, vol. 152, pp. 1099-1108, 2020.

[8] H. Guo, Y. Xu, X. Zhang, X. Zhou and H. Chen, "Transmission characteristics of exergy for novel compressed air energy storage systems-from compression and expansion sections to the whole system," Energy, vol. 193, p. 116798, 2020.

[9] W. Daniel, Methods for design and application of adiabatic compressed air energy:storage based on dynamic modeling., Oberhausen: Laufen, 2011.

[10] Herbst, H C; Stys, Z S, "Huntorf 290 MW Air storage System Energy," Proceedings of the compressed air energy storage symposium, p. 17, 1978.

[11] Pollak, R., "History of first U.S. Compressed Air Energy Storage (CAES) plant (110MW 26h)," Construction. Palo Alto, vol. 2, 1994.

[12] Pan,L.;Oldenburg CM, "Porous media compressed-air energy storage (PM-CAES):theory and simulation of the coupled wellbore-reservoir system.," Transport in Porous Media, vol. 97, pp. 201-21, 2013.

[13] Budt. M.; Wolf, D, "LTA-CAES - a low-temperature approach to adiabatic," Appl Energy, vol. 125, pp. 158-64, 2014. 


\section{International Advanced Research Journal in Science, Engineering and Technology}

Vol. 8, Issue 2, February 2021

\section{DOI: $10.17148 /$ IARJSET.2021.8205}

[14] Haughey, C, "In Gaelectric energy storage: The missing link,” 2015.

[15] Guo,C.; Pan,L.; Oldenburg,C.M.; Zhang,K.; Li, C.; Li,Y. "Comparison of compressed air energy storage process in aquifers and caverns based on the Huntorf CAES plant," Applied Energy, vol. 181, pp. 342-56, 2016.

[16] Oldenburg, C.M.; Pan,L., "Compressed air energy storage in depleted natural gas reservoirs: effects of porous media and gas mixing," in 2015 AGU fall meeting, Agu, 2015.

[17] Guo,C.; Zhang, K.; Li, C., "Influence of permeability on the initial gas bubble evolution in compressed air energy storage in aquifers.," TOUGH symposium, 2015.

[18] Dostal,V.; Driscoll, M.J.; Hejzlar, P., "A supercritical carbon dioxide cycle for next generation nuclear reactors," Massachusetts Institute of Technology, PhD dissertation, Massachusetts, 2004.

[19] Wang, M.; Zhao, P.; Wu, Y.; Dai, Y.; "Performance analysis of a novel energy storage system based on liquid carbon dioxide," Applied Thermal Energy, vol. 91, pp. 812-23, 2015 .

[20] Zhou, Q.; Birkholzer, J. ; Tsang, C.F.; Rutqvist, J.;“A method for quick assessment of CO2 storage capacity in closed and semi-closed saline formations," Int J Greenh Gas Con, vol. 2, no. 4, pp. 626-39, 2008.

[21] Liu, H.; He, Q.; Borgia, A.; Pan, L.; Oldenburg, C.M.;"Thermodynamic Analysis of a compressed carbon dioxide energy storage system using two saline aquifers at different depths as storage reservoirs," Energy Conversion \& Management, vol. 127, pp. 149-159, 206.

[22] Liu, JL.; Wang, JH.; “A comparative research of two adiabatic compressed air energy storage systems," Energy Conversion Management, vol. 108 , pp. 566-78, 2016.

[23] Succar, S.; Williams, R.H.;“Compressed air energy storage: theory,resources, and applications for wind power," Report no.8, Princeton environmental institute, 2008.

[24] T. Tanuma, Advances in Steam Turbines for Modern Power Plants, Elsevier Ltd., 2017.

[25] G. Ma, H. Lu, G. Cui and K. Huang, "Multi-stage Rankine cycle (MSRC) model for LNG cold-energy power generation system,” Energy Part B, vol. 165 , pp. 673-688, 2018

[26] Liu, Z., Liu, Z., Yang, X., Zhai, H., \& Yang, X. (2020). Advanced exergy and exergoeconomic analysis of a novel liquid carbon dioxide energy storage system. Energy Conversion and Management, 205, 112391. https://doi.org/10.1016/j.enconman.2019.112391

[27] Liu, Z., Liu, B., Guo, J., Xin, X., \& Yang, X. (2019). Conventional and advanced exergy analysis of a novel trans critical compressed carbon dioxide energy storage system. Energy Conversion and Management, 198, 111807. https://doi.org/10.1016/j.enconman.2019.111807

[28] Liu, Z., Yang, X., Jia, W., Li, H., \& Yang, X. (2020). Justification of CO2 as the working fluid for a compressed gas energy storage system: A thermodynamic and economic study. Journal of Energy Storage, 27, 101132. https://doi.org/10.1016/j.est.2019.101132

[29] Liu, Z., Liu, Z., Xin, X. and Yang, X., 2020. Proposal and Assessment of a Novel Carbon Dioxide Energy Storage System with Electrical Thermal Storage and Ejector Condensing Cycle: Energy and Exergy Analysis. Applied Energy, vol 269, p.115067,2020. 